\title{
Skeletal damage in reef corals: relating resistance to colony morphology
}

\author{
Paul A. Marshall* \\ CRC Neel Research Centre and Department of Tropical Envirenment Studies and Ceegraphy, James Ceek University, \\ Townsville, Queessland 4811, Australia
}

\begin{abstract}
Corals vary in their ability to resist breakage from mechanical force. Biomechanical theory predicts that resistance to mechanical injury should be determined by the morphological properties of coral colonies. However, a general model to predict resistance of corals to mechanical impact from structural characteristics hes been lacking. In order to determine whether resistance can be pre: dacted from colony structure, I use a suite of 6 vanables - skeletal density, branch thickness, branch spacing, branch length, colony height and colony (projected) area-to quantitatively describe the structure of colonies from 12 species of scleractinian coral. Experimental analysis of the resistance of colonies from each species, which range from massive and tabular growth forms to various branching models. showed that damage susceptibility varied widely. Resistance ranged from very high for species such as Leptoria phrygia, Porites cylindrica and Porites spp. in which there was no reduction in colony area as a result of mechanical stress, to low in species such as Pocillopora damicornis, Seriatopora hystrix and Montipora sp. which suffered over $60 \%$ damage. Regression tree analysis revealed a strong relationship between resistance and colony morphology, producing a model which accounted for $76 \%$ of the variation in resistance using only 4 of the structural variables: colony height, branch thickness, branch spacing and colony area. Skeletal density and branch length were relatively unimportant in determining susceptibility to breakage. The regression tree model showed potential tor development as a predictive tool in reef management, as it was able to predict susceptibility to breakage of corals using 4 easily measured morphological variables with $57 \%$ reliability (estimated by cross-validation]
\end{abstract}

KEY WORDS: Coral - Skeletal density - Structure - Disturbance - Biomechanics + Morphology - Reef management

\section{INTRODUCTION}

Scleractimian corals, the dominant benthic organisms in most coral reefs, play key roles in habitat provision and reef construction (Grassle 1973, Endean 1976. Davies 1983). However, their rigid aragonitic skeleton is brittle and readily broken when exposed to mechanical forces associated with physical disturbances (Wainwright et al. 1976. Chamberlain 1978). A wide range of physical disturbances can cause structural damage to corals, including natural events such as

- Present addidess Great Barrier Reef Manne Park Authority. PO Box 1379, Townswille, Queensland 4810, Austratia.

E-matl-p marshallatgbpmps.gov.au storms and cyciones (e.g. Woodley et al. 1981, Dollar \& Tribble 1993), and human activities such as boat anchoring fe.g. Davis 1977, Palaganas 1991, Allen 1992), SCUBA diving and snorkelling (e.g. Hawkins \& Roberts 1992, Chadwick-Furman 1997, Rouphael \& Inglis 1998,. Not all corals are affected equally by physical stress, and those with obviously different morphologies commonly differ in their response to mechanical force (Stoddart 1963, Woodley et al. 1961. Liddle \& Kay 1987 .

Variation in the response of corals to mechanical stress has significant ecological implications. In some situations, differential damage and mortality resulting from disturbance can be important in preventing a small subset of species from dominating a coral assem. blage through competitive exclusion (Connell 1978). 
Improved understanding of the relationship between structural characteristics of corais and their susceptibility to damage may further clarify mechanisms by which physical disturbance affects the species diversity ot cotal assemblages.

The response of scieractinian corals to mechanical stress has important life-history implications. Structural damage results in a decrease in colony size and in the production of tragments (Highsmith 1982, Hughes $\&$ Connell 1987 ). The costs of demage to a coral include allocation of energy to repair injured tissue (Rinkevich \& Loya 1989), increased risk of colonization by epilithic algae or bioeroders (Balk et al. 1977, Bak \& StewardVan Es 1980) and reduced reptoductive output (Hall \& Hughes 1996). A cotal can also benefit from breakage if tragments that are produced are able to initiate new coloules. Indeed, for some species, fragmentation re. sults in higher rates of recruitment success compared with sexually produced larvae (Highsmith 1982). The extent to which breakage is adaptive in the life history of corals is stili debated (Hughes et al. 1992), but it is likely to vary between species and across habitats. In most situations the relative costs and benefits of breakage to a coral will depend on the extent of structural damage, which is determined by a coral's ability to withstand mechanical force.

The response of a cotal to mechanical force is determined by 3 properties: resiatance, resilience and stability (after Conneil \& Sousa 1983, Underwovd 1989). Resilience and stability describe the processes of recovery, whilst resistance is the property which determines whether of not a coral will show any initial response to a particular disturbance. This fundamental property of organisms exposed to stress has also been called inertia of persistence, particularly in relation to population - or community-levei response to disturbance (Underwood 1989). Basic principles of blomechanics suggest that resistance in rigid organisms such as scleractininan corals is determined by structural properties of the coral colony. Generally, these principles are borne out by observations of differential damage among corals exposed to physical disturbances of various types. Large storms (Woodley et al. 1981 . Rogers 1993, Connell et al. 1997), boat anchoring (Davis 1977, Palnganas 1991), reef walking (Liddle \& Kay 1987 , Hawkins \& Roberts 1993 ) and recreational diving (Hawkins \& Roberts 1992, Reigl \& Reigl 1996, Rouphael $A$ inglis 1998) have all been reported to damage corals with finer architecture, such as tabular or branching Acropora, more than corals with a solid architecture, such as Porites and favids.

However, our ability to predict the resistance of a coral to mechanical forces remains poor, and depends upon arbitrary categories of colony morphology which have vague operational boundaries fi.e. arborescent. digitate, tabulat, massive, etc.). Mote analytical at. tempts at relating resistance to structural properties of corals have mostly focused on the effect of skeletal density on strength (Chamberlain 1978, Schuhmacher 1964). Other studies have examined the effects of the morphology of individual structural elements (i.e. branches) on susceptibility to breakage (Liddle \& Kay 1987), of have compared the effects of skeletal density with morphology for a few closely related species (Schuhmocher \& Plewka 1981b). However, none of these studies have sought general pnnciples or models which explain resistance in terms of quantifiable struchural characteristics of coral colonies.

The relationship between colony architecture and resistance also has implications tor management at coral reets. If colony structure is a reliabie predictor of resistance to physical damage it may be possible to use information about the morphological camposition of coral assumblages to prectict the susceptibility at corals to breakage. In reef areas which are managed to protect against the impacts of human activities such as boat anchoring, reef walking and diving, an ability to predict the effects of anthropogenic physical disturbances can be critical to informed and effective man. agement (Craik et al. 1990).

In this study, I investigate the biomechanical basis of resistance of corals to mechanical damage. I identify a suite of quantitative variables which describe morphological and material properties of corals such as branch morphology, branch arrangement and skeletal density. To test the resistance of corals I then measure structural damage in colonies exposed to experimental mechanical impact. I examine the relationship between resistance and colony structure, and develop a statistical model using non-linear classification techuigues to predict damage susceptibility from simple morphological characteristics of coral colonies.

\section{METHODS}

Twelve species of scleractinian corals were selected for use in the study. The 12 species represent a range of morphologies and families that are common on the Great Barrier Reef (GBR) (Veron 1986) (Fig 1). Six colonies of each species were selected at sheltered sites around One Tree lsland $\left(23^{\circ} 30^{\circ} \mathrm{S}, 152^{\circ} 03^{\circ}\right.$ E), a small offshore cay with well-developed reel in the southern CBR. Six structural characteristics-skeletal density and 5 morphological variables-were measured for each colony. The 5 morphometric variables were simple to measure in the bield and represented characteristics of both branch morphology and branch arrangement (colony architecture): branch length, branch thickness, branch spacing, colony height and 

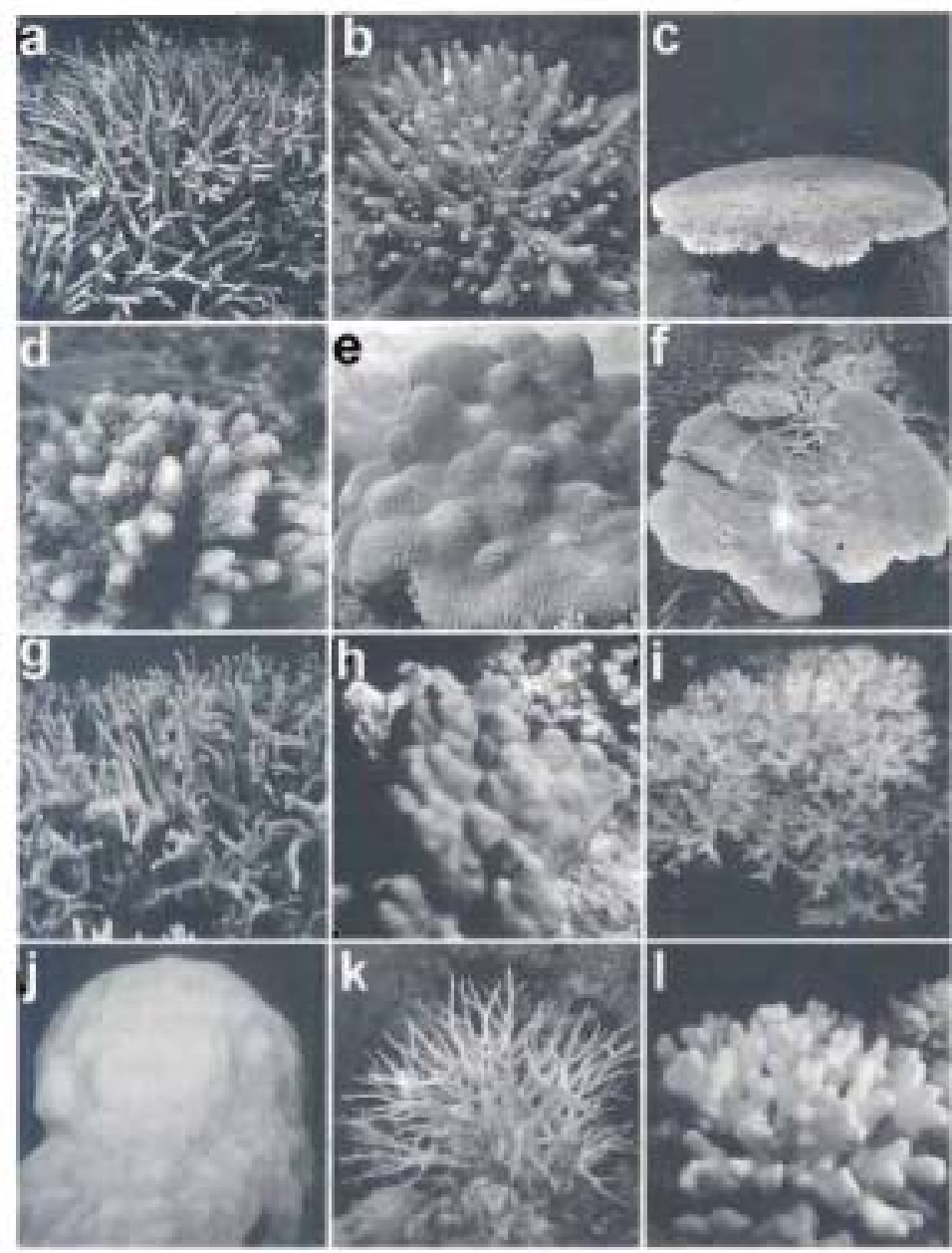

Fa1. I. Representativw colonies from each of the 12 species ot Scleractinia used in the study. Growth form (in brackets) affer Veron (19e6) (a) Acropora farmose foranchingh (b) Acropota bumilis fbranchingl. (c) Acropora hyacinthis iplate)i (di) Acropore palifera (branching! (e) Leptoria phrygia (massive) if Montipora sp. iplatey (g) Pantes cylendrica (branchung)i (h) Porties annae isasaive)i if Pocillopora damicornis (branchiog)! (i) Porites spp (massive) (kj Senatopora hystrix fbranchingh (1) Styiophora pistilleta (branching). (Photographs a, b, f, g, L, ) \& \& I courtesy of JE.N. Veran. Photographs $c$, d \& e courtesy of D. Wachenield!

colony iplanari area. The colonies that were selected were of average size for each species in this location (determined from pilot surveys), and were located in water $<10 \mathrm{~m}$ deep.

Measuremeat of structural characteristics. The skeletal density of each colony was calculated from 3 replicate sub-samples per colony. Several of the branching species were known to exhibit gradients in skeletal density within the corallum (Oliver 1984, Hughes 1987). Samples of the skeleton taken from these species included sections of varying density across the expected range within the colony. For exam. ple. in the branching species with axial gradients in skeletal density, the samples were branch sections extending from the base to the tip of the branch. Thus, the density measure for each sample is integrative, providing an average skeletal density for the colony.

Samples were cleaned of tissue by immersion in a chlorine bleach bath, air dried for 5 to $7 \mathrm{~d}$, and weighed to the nearest gram. The volume of each sample was determined by volumetric displacement in fresh water. Samples were coated in paraffin wax priot to measurement to prevent water infiltration of skeletal pores, an important influence on gross skeletal density and strength (Wainwright et al. 1976) The measured volumes were adjusted for the contribution of paraffin wax used to coat each sample, which was calculated from the mass of wax adhering to the sample and the known density of paraffin wax. Skeletal density ( $\mathrm{kc}$ $\mathrm{m}^{-3}$ ) was then caiculated for each sample, representing the ratio of aragonitic matrix to pore space in the skeleton sample.

The large range of structure and form which is typical of most coral assemblages poses particular problems when comparing the morphology of different colonies. In particular, it has proven difficult to develop generalised morphometric models which permit quantitative comparisons between colonies with vastly different architectural models or growth forms (such as tabulate, arborescent and massive). As a result, previous studies have either confined their comparisons to specles that are simlar in growth form le.g. Chamberlain \& Graus 1975, Schuhmacher \& Plewka 1981a), or have resorted to qualitative categories of general growth form leg. Kay 8 Liddle 19a9). Based on work by Graus et al. [1977), t bave aftempted to overcome this limitation by modeling all colony forms as geometric variants of a basic branching plan. Using this approach, colonies with either massive growth form (e.g. Porites sp, Leptoria phrygia) or tabular growth form le.g. Montipora sp. Acropora hyacinthus\} are considered equivalent to a single, vertically growing branch, and are described as nonbranching. Most other growth forms are considered to have multiple branches, and are described as branching species. Encrusting corals were not represented in this study.

The morphological variables were measured in situ. or calculated directly from in situ measturements. In each colony 5 branches were selected haphazardly to measure branch thickness, branch length and branch spacing. Although there can be substantial intra-co- 
lony wanation in these variables. I was primarily interested in whole-colony response to mechanical stress. and an average value for each voriable was derived for each colony. Branch thickness was estimated by calculating the cross-sectionel area, assuming an ellipsoid cross-section and using the majot and minor branch diameters. Branch diameters were measured at the base of the selected branches, just above the first major bifurcation above the colony base. Branch length was a direct linear measurement from the branch base las defined above) to the branch tip. Branch spacing was the distance between the tip of the selected branch and that of the nearest neighbouring branch. Colony height was a single measurement for each colony, and was measured as the maximum vertical extension of skeletal elements (not total height above substratum).

Planar area was measured from video images taken vertically above each colony betore and affer distur: bance. Video stills were captured using an external Snappy (Play Incorporated) video capture device, and processed in a photograph editing package to delineate colony perimeter. Total planar area was then calculated using Image Tool, a public domain image analysis soltware package devoloped by the University of Texas Health Sclence Centre at San Antonio (UTH. SCSA 1996).

Experimental disturbance. To test the resistance of each colony to physical disturbance, a standardised force was applied to each coral colony using a specially developed test apparatus similar to that used to simulate the effects of trampling on terrestrial flora (Wagar 1967, Kellomaki 1973). The impact apparatus consisted of a $12.5 \mathrm{~kg}$ metal disk with basal area of $180 \mathrm{~cm}^{3}$, which slid down a guide pole $1.2 \mathrm{~m}$ long. The base of the vertical guide pole was placed on top of the subject colony and the disk was relensed, falling along the pole to apply a single, instantaneous vertical force to the coral. The mass, size and application of the weight simulated a moderate-sized boat anchor falling onto a coral.

The response of each coral colony to the test distur: bance was measured by the relative change in planar (projected) area of the collony. Planar area was mevin: sured prior to disturbance, and then immediately after the test disturbence. Post-disturbance measurements were based on the planar area of the original coral skeleton that remained intect and attached li.e. frag. ments were removed). Planar area estimates the area of benthic space controlled either directly or indirectly by a sessile organism (pre-emptive space). and is therefore an important indicator of the relative hitness of a coral colony in a reef assemblage (Jackson 1979 ). Additionally, changes in planar area can be used to measure damage across a range of growth forms. Relative damage was defined as the absolute change in planar area divided by the initial planar area of the colony.

Analyses. The relotionship between resistance and structural characteristics of colonies was tesied using regression techniques, Colonies were not grouped by species for these analyses, since 1 sought a model which would predict resistance from quantifiable mor: phological variables independent of qualitative categories. Simple linear regressions were used to relate damage caused by the impact treatment to each of the structure variables in turn. The degree of linear association between structural variables was quantifled using the Pearsen correlation coefficient. Strong correlation between predictor variables rendered multiple linear regression inappropriate for examining the relationship between raw structural characteristics and resistance Instead, principal componunt analysis (PCA) was used to reduce the 6 structural charecteristics to a smaller number of uncorrelated components. These components were then used in multiple Linear regression analysis to test for a relationship between damage and the combined structural characteristics.

Blomechanical theory suggests that the interactions between morphological characteristics are important in determining structural properties of an organism. Residual plots indicaled that the relationships between variables was complex, suggesting that a non-linear technique that was insensitive to heteroscedasticity might better represent the structure-resistance relationship. Regression tree analysis explains variation of a single response variable in terms of multiple explanatory variables, without being limited to linear relationships and withoul strict requirements of homoscedasticity (De'ath \& Frabricius 2000). Regression trees were thus ased to explote non-linear relation. ships between the structure variables and damage.

The regression tree is constructed by repeated binary splitting of the data. At each split the model tests all predictor variables to determine the variable and its value which maximises the sums of squared differences between the 2 resulting sets of response walues. In this way the model determines a non-linear sequence of binary splits which explains the maximum amount of variation in the response variabie. The optimal size of the regression treo model is estimated by plotting the predicted residual sums of squares for the model against tree size and identifying the minima. The power of the model as a predictive fool is tested in an internal cross-validation procedure, fn this procedure. the tree is generated from a randomly selected subset $(90 \%)$ of the data, and its predictive ability is tested on the $10 \%$ of the data which were excluded from model generation. An estimate of the mean and standard error toz cross-validated model error was derived by bootstrapping $(n=50)$. 
PCA was used to explore the correlation among structural characteristics of coral colonies, and to examine the taxonomic consistency in coloay structure. An ordination plot of component scores for each colony was producted using the first 2 components from a PCA of the 6 structural variables. Conflidence ellipses (90\%) were then plotted for species groups and the relationships between species groupings wore examined. The degree of reliability with which colonies of the samer species are grouped in the PCA provides an indication of the validity of using the chosen suite of variables to describe the structure of colonies diflering widely in growth form.

\section{RESULTS}

\section{Structural characteristies of corals}

\section{Skeletal density}

Skeletal density ranged from a mean of $1226 \mathrm{~kg} \mathrm{~m}^{-3}$ for Porites annae to $2201 \mathrm{~kg} \mathrm{~m}^{-3}$ for Seriafopora bystrix (Table 1). The 3 species of Pocilloporidae had the highest skeletal densities, followed by the plate-forming species, Acropora hyacinthus and Montipora tuberculosa. The other species were of intermediate skeletal densities $\left(1387\right.$ to $\left.1610 \mathrm{~kg} \mathrm{~m}^{-3}\right)$.

\section{Colony area}

Planar colony area ranged from a mean of $210 \mathrm{~cm}^{2}$ for Porites spp. to $1085 \mathrm{~cm}^{2}$ for Acropora hyacinthus (Table 1). The plate-forming species. A hyacinthus and Montipora fuberculosa were, on average, the 2 largest species, with an average colony area $>900 \mathrm{~cm}^{2}$. Mean colony area exceeded $500 \mathrm{~cm}^{2}$ for Leploria phrygia. Pontes cylindrica and Acropora formosa. The pocilloporid species Stylophora pistillata, Pocillopora damicomis and Seriatopora hystrix were among the smallest species in the study, with a mean colony area $<400 \mathrm{~cm}^{2}$

\section{Colony height}

Colony height ranged from a mean of $0.5 \mathrm{~cm}$ for Montipora sp. to $29 \mathrm{~cm}$ for Leptoria phrygia (Table 1). The plate-forming species Montipora sp. and Acropora byacinthus were the 2 shortest species, followed by Acropora humilis, Pocillopora damicornis and Seriatopora hystrix. The tallest species were L phrygia, Acropora formosa and Porites cylindrica, all with a mean colony height $>26 \mathrm{~cm}$.

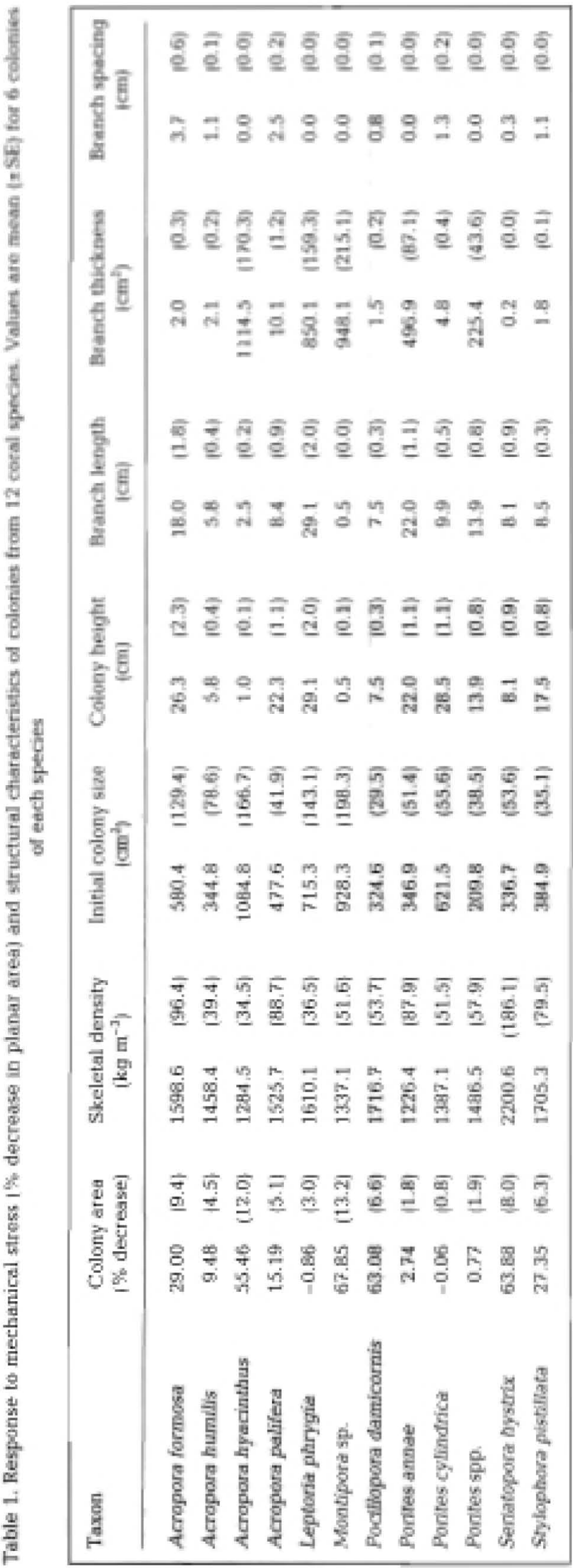


Branch length

Branch length and colony height are closely related (Pearson correlation $=0.744 . p=0.000$ ), particularly for colonies with growth forms that were geometrically characterised as single, non-dividing, vertically growing branches. Therefore branch length showed a similat range to colony height, varying from a mean of $0.5 \mathrm{~cm}$ (Montipora sp.j to over $29 \mathrm{~cm}$ (Leptoria phrygia) (Table 11. Branch length in colonies with branching growth form ranged from $5.8 \mathrm{~cm}$ (Acropora humilis) to $18 \mathrm{~cm}$ (Acopora formosa). Acropora palifera colonies used in this study wore distinctly ramose fi.e. secondary branching was commonl, with an overage branch length of $8.4 \mathrm{~cm}$.

\section{Branch thickness}

Branch cross-sectional area was the most variable of the morphological characteristics measured, with average branch cross-section rangiag from $0.2 \mathrm{~cm}^{2}$ in Seriafopora hystrix to $1115 \mathrm{~cm}^{2}$ in Acropora hyacinthus. This large range is due in part to the geometric definition of colonies in which massive and tabular growth forms were classifled as single, vertically growiag branches isee 'Methods'). In these carals, the crass-sectional area of the colony is identical to the branch cross-sectional area. Species formed 2 distinct groups based on branch thickness. The 7 species with a branching afchitecture had an average cross-sectional area close to or less than $10 \mathrm{~cm}^{2}$. The remaining 5 species, comprising massive and tabular species, had branches $>200 \mathrm{~cm}^{2}$ in cross section (Table 1).

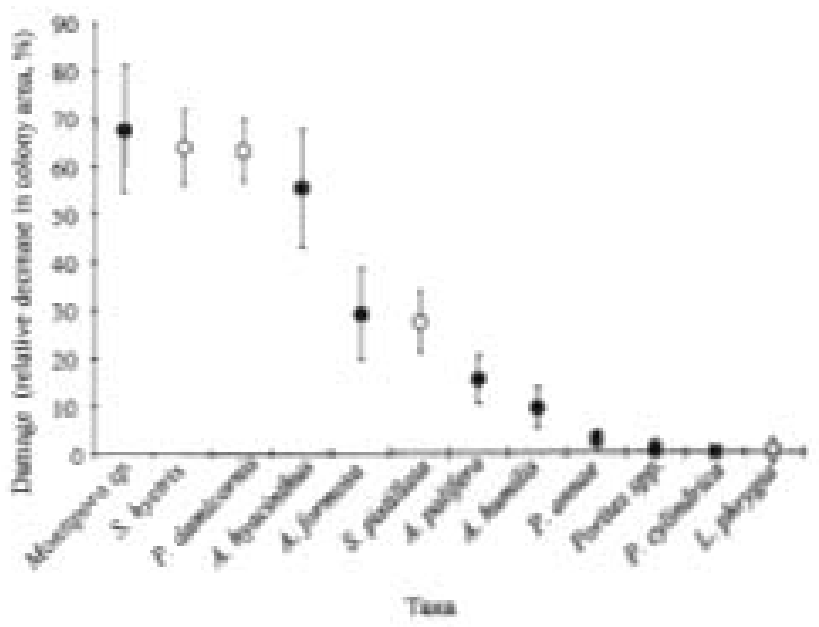

Fig. 2 Mean (4SE) reduction is planar area of 12 species of scleractina caused by the same mechanical force in * 6 colonies per species). Symbols show tamilies: (•) Acroperidae: (o) Pocilloporidae; (a) Poritidae, ial Favuidae
Branch spacing

The distance between adjacent branches is an important variable for distinguishing among ramose species. Mean branch spacing varied from $0.3 \mathrm{~cm}$ (Seriatopora hystrix) to $3.7 \mathrm{~cm}$ (Acropora formosa) in the 7 species with a branching growth form (Table 1, Fig. 1). Acropora palifera was the next most openly branched species after $A$. formosa. The most compact of the branching species after S. hystrix was Pocillopora dam. icornis, with a mean branch spacing of $0,8 \mathrm{~cm}$, Porites cylindrica, Stylophora pistillata and Acropora humilis were intermediate, ranging from 1.1 to $1.3 \mathrm{~cm}$. The 5 species with massive or tabular growth form were characterised geometrically as single branches, and were given a zero value for branch spacing.

\section{Colony damage - resistance to mechanical force}

There was large variation in resistance to mechanical stress among the corals tested, with colonies suffering reductions in planar area (damage) of between 0 and $100 \%$. Six species contained undamaged colonies: Leptoria phrygia, Porites annae, Porites sp., Porites cyilindrice, Acropora farmosa and Acropora humilis. Colonies which were totally damaged (L.e. colony area reduced by $100 \%$ ) during the mechanical impact tests were from 3 specles: Acropora hyacinthus, Montipora fuberculasa and Seriatopora hystrix.

The average reduction in planar area differed significantly between species (ANOVA: $\mathrm{df}=11 . F=14.8$. $p=0.000 \%$, ranging from 0 to $68 \%$ (Table 1. Fig. 2). The species with the highest resistance ( $<5 \%$ damage) to mechanical stress were Leptoria phrygia and the 3 species of Porites P. cylindrica, Porites sp. P. annae. All were characterised by a massive (solid) architecture. except $P$. cylindrica, which was branched. The species least resistant to physical impact p $>50 \%$ damage) were Acropora hyacinthus, Pocillopora damicernis. Seriatopora hystrix and Montipora tuberculosa. Colonies of $\mathbf{A}$. byacinthus and $\mathbf{M}$. tuberculosa had a tabulate of plating architecture, while the 2 Pocilloporid species were branched. Species of intermediate resistance (mean damage range: 9 to $29 \%$ ) all had architectural models characterised by branching Acropora tormosa, Stylophora pistillata, Acropora palifera and Acropona humilis.

\section{Relating colony structure and resistance}

Resistance to mechanical damage in corals was not reliably predicted by any morphological variable alone. The maximum amount of variation in damage 
explained by tineat telationship with a single morphological variable was $35 \%$ (colony height). Branch length was less useful again for predicting resistance, with $r^{2}=0.25$. The remaining 4 variables iskeletal density, colony size, branch thickness and branch spacing] each explained less than $5 \%$ of the observed variation in response to experimental mechanical stress (Fig. 3).

Residual plots indicated complex relationships between the structure variables, suggesting that multiple lineer regression against the raw predictor variables. was inappropriate. PCA reduced these 6 related variables to 3 independent components with eigenvalues $>1$ that together explained $77 \%$ of the variation (Table 2). The first component, which explained $31 \%$ of the variation in the data. correlated strongly with branch cross-sectional area, branch spacing. colony size and skeletal density, Component 2 explained an additional $29 \%$ of the variation. and separated the data on the basis of colony height and branch length.
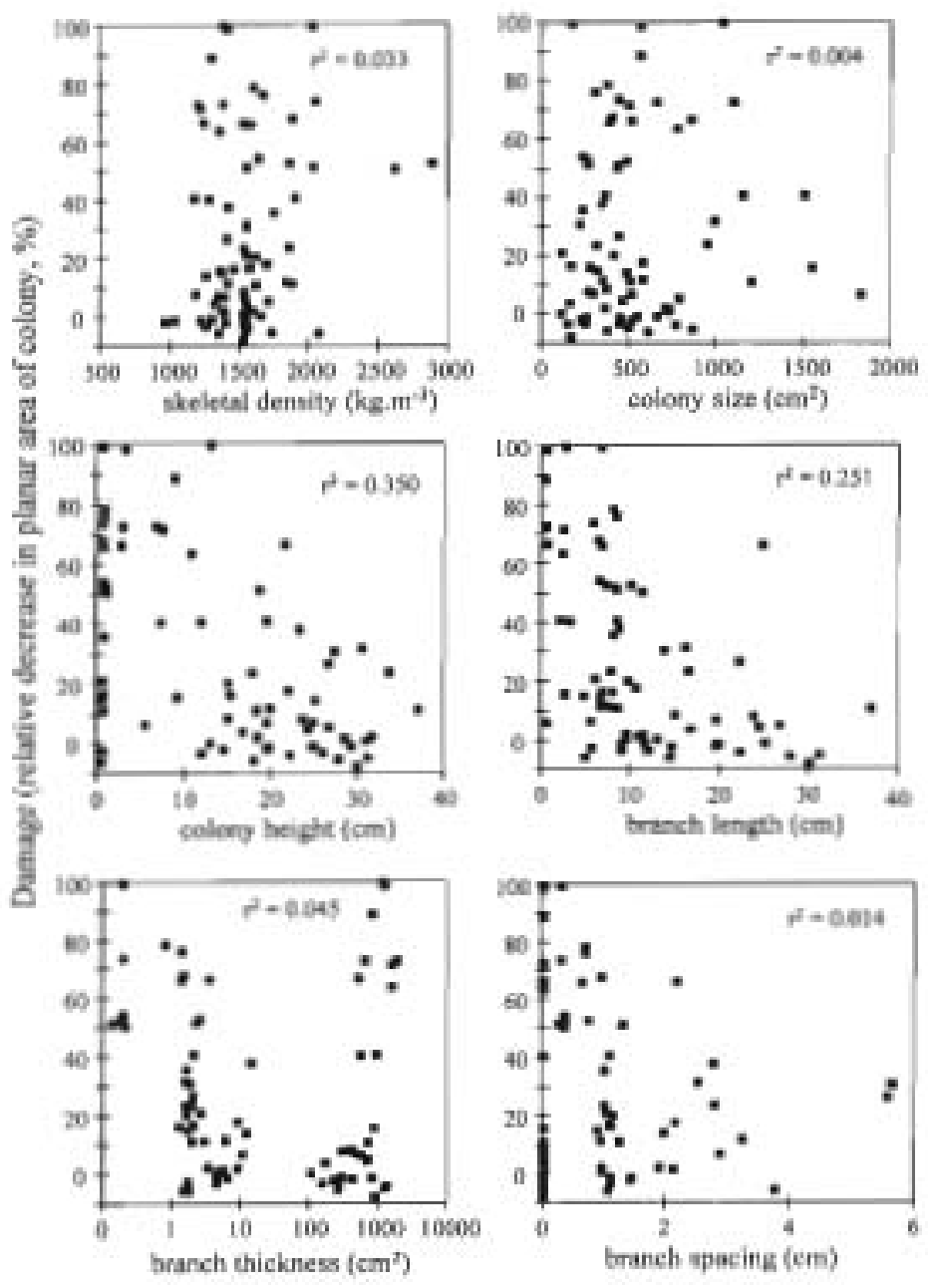

Fig. 3. Damage against each marphological vartable, showing cesifticient of variation $\left(\mathrm{r}^{2}\right)$ from univariate linear regressions Note logia scele for branch thickness
Component 3 explained a further $17 \%$ of variation in the data, and was addinonally correlated with branch spacing, colony suze and branch length.

Although the first 3 principol components together explained $77 \%$ of the variation in the predictor variables, they were not effective at representing variation in resistance. The multiple linear regression of resistance against the 3 principal components was highly significant $(p=0.000)$, but the regression explained only $34 \%$ of the variation in resistance $f \alpha=0.278$, $\beta_{1}=-0.066, \beta_{2}=-0.168, \beta_{2}-0.023, r^{2}=0.343$. The predictuve vafue of the morphological variables, either alone or in linear combination, was therefore relatively low.

Regression trees were much more effective at representing the relationship between colony structure and resistance (Fig. 4). Regression tree analysis yielded a model which represented $76 \%$ of the variation in the date using only 4 morphological variables. The regres. sion tree model reliably predicted tesistance from colony structure. with cross-validated reliability averaging $57 \%(+0.7 \%)$

The optimal regression tree divided the 72 colonies into 5 groups on the basis of colony height, branch thickness, branch spacing and colony area (Fig. 4). The first drvaion of the tree separated colonies $>11.6 \mathrm{~cm}$ in height. Tall colonies (>11.6 cm) were subsequently divided on the basis of branch cross-sectional area. producing leaves (terminal ends of regression tree stems) with very different values of the response va. riable, damage. Thus, colonies that were $>11.6 \mathrm{~cm}$ in height and which had a mean branch thickness $>3.9 \mathrm{~cm}$ formed a terminal group that was most resis. tant to physical impact (mean damage $=3.6 \pm 0.8 \% \mathrm{SE}$ : $n=29$ ). Colonies of the same height, but which had thinner branches ( $<3.9 \mathrm{~mm}$ ), formed a group of intermediate resistance $\{26.1=3.4 \%$ SE; $\mathrm{n}=13)$. The regression model split colonies $<11.6 \mathrm{~cm}$ in height into

Toble 2. Results trom principal component analysis of 6 strecture variables colony size. coloey height, branch spectng. branch length, branch thickness and skeletal densily. Only components with eigervalue $>1$ are shown. Vanable loadings with absolute values 20.4 are shown in bold

\begin{tabular}{|c|c|c|c|}
\hline \multirow[t]{2}{*}{ Explanatory variable } & \multicolumn{3}{|c|}{ Composent } \\
\hline & 1 & 2 & 3 \\
\hline Colony sixe & 0.59 & -0.18 & -0.46 \\
\hline Colony beight & -0.14 & -0.94 & -0.09 \\
\hline Branch spacing & -0.67 & -0.23 & -0.61 \\
\hline Branch length & -0.23 & -0.77 & 0.53 \\
\hline Branch thicikness & 0.84 & -018 & 0.17 \\
\hline Skehetal deasity & -0.52 & 0.40 & 0.34 \\
\hline Eigenvalue & 1. 36 & 1.75 & 1.02 \\
\hline of variance & 31.02 & 29.19 & 16.92 \\
\hline
\end{tabular}




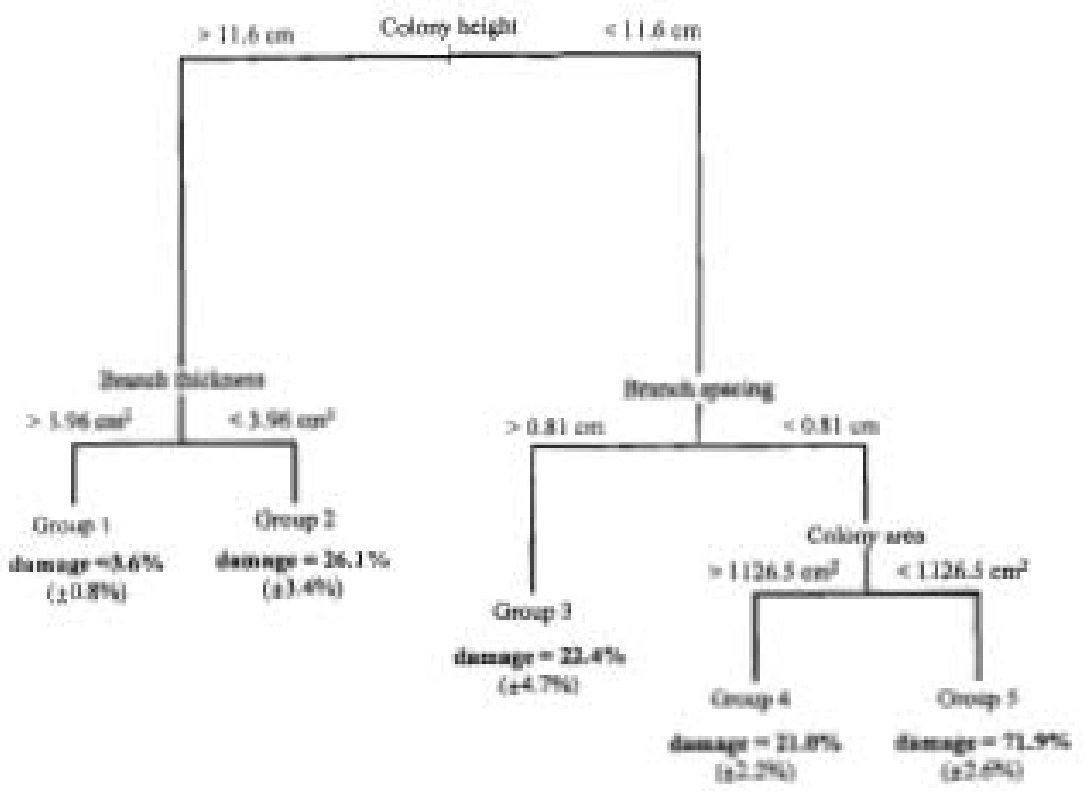

Fig. 4. Regresion tree medel of the relationship betwess damage and structaral chatscteristics of corals ferror -6.24$)$. The model predicts damage with $57 \mathrm{~s}$ reliabelity ictons-validation errot $=0.43 \neq 0.01$ ) asing 4 morphological vartables. colony height, branch thickness, branch spacing and colony aree

Pocillopora damicornis. Camponent 1 ajso separates the tall solid colonies of Leptoria phrygia and Porites annae from tall branching colonies of Parites cylindrica and Acropore formosa. Component 2, cot: relaning with colony height and branch length, as well as skeletal density, reveals differences in structure between branching colonies of A. formosa, Acropora palifera and Stylophora pistillata. It also separates colonies of Porites spp. from other colonies with a massive growth form. Confidence ellipses $(90 \%)$ further illustrate the effectiveness of the $2 \mathrm{com}$ ponents in representing similarities between colonies of the same species. These results indicate that there is strong taxonomic consistency in the grouping of coral coloaies on the basis of structural characteristics and validate the use of a simplified geometric branching model to represeat the range of growth forms.

The taxonomic consistency of corals grouped by structural similarities suggested that the predictions of the regres *

2 groups based on branch spacing. Short colonies $(<11.6 \mathrm{~cm}$ ) with branch spacing $>0.81 \mathrm{~cm}$ were subdivided into a terminal group with intermediate resistance $(22.4 \pm 4.7 \%$ SE; $n=8)$. Short colonies with branch spacing $<0.81 \mathrm{~cm}$ were further split an the basis of colony size into the final 2 leaves. Colonies c1126.5 $\mathrm{cm}^{2}$ in area formed a terminal group with intermediate damage $(21.0 \neq 2.2 \% ; n=4)$ while coloaies $>1126.5 \mathrm{~cm}^{2}$ were those with the highest level of dainage $(72+2.6 \%, n=18)$. In other words, corals with least resistance to physical impact ithose which exhibited the greatest damage) were colonies that were $<11.6 \mathrm{~cm}$ in height with narrowly spaced branches |<0.81 branch spacing) and $>1126.5 \mathrm{~cm}^{2}$ in plenar area (Fig, 4).

\section{Taxonomic consistency of colony structure and resistance}

The PCA scores plot shows that the first 2 principal components are effective at explaining most $(60 \%)$ of the variation in stroctural characteristics andmong the coral colonies, and that moch of the structure in the data relates to species groupings of coloaies (Mig. 5). Component 1, strongly correlated with branch thick. ness, colony area, branch spacing and skeletal density, separates low plate-forming colonies of Montipara sp. and Acropora hyacinthus from the small branching colonies of Acropota humilis, Seriatopora hystrix and sion tree model could be usefully interpreted in relation to coral taxa comprising each group (Table 3). Group 1 (mean damege $=3.6 \%$ ) predicted by the regression tree model comprised the 3 species with massive growth farm (Panites sp. Leptoria phrygia and Porites annate) plus colonies from the thick. branched species Acropora palifer and Porites cylindrice Group 2 (mean damage $=26.1 \%$ ) contained the tiranching species Acropora formosa and Stylophora pistillata. Group 3 (mean damage $=22.4 \%$ ) was characterised by 2 different branching species: Acropora humilis and 2 colonies of Pocillopora damicornis. Group 4 (mean damage $=21.0 \%$ ) contained only 4 colonies from the 2 plate-forming species Acropora hyacinthus and Montipora sp. Group 5 contained the colonies with lowest resistance to damage imean dam. age $=71.9 \%$ ), and included colonies of $A$. hyacinthus and Montipora sp. as well as the small branching species $P$. damicomis and Seriatopora hystrix.

\section{Discussion}

Although scleractinian corals feature a wide range of growth strategies and colony shapes, the results of this study demonstrate that the structural characteristics of colonies from a range of species can be effectively represented by 6 quantifable variables. These variables (colony area, colony height, branch length. branch thickness, branch spacing, skeletal density) 


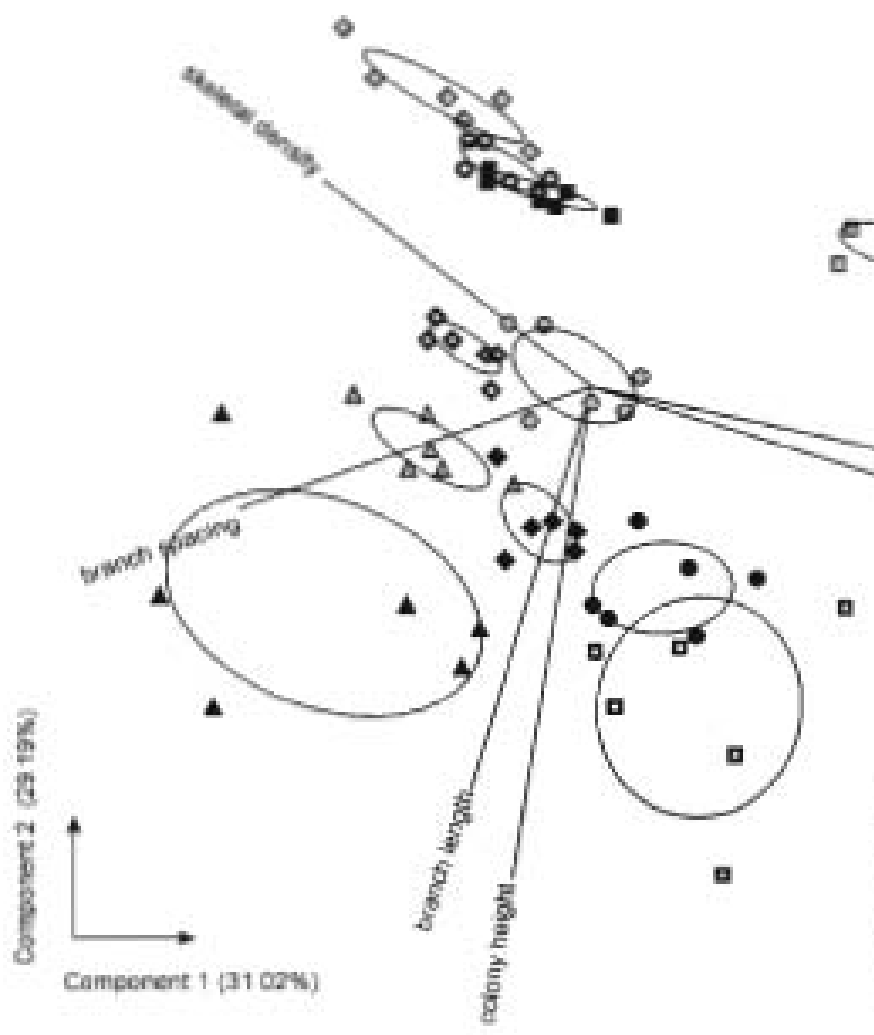

describe colony structure without recourse to qualitative categories such as growth form. By representing all colonies, regardless of overail form or shape, as geometric variants of a basic branching plan, colony structure can be compared between and within species with vastly different growth strategies. This scheme may not be appropriate for all corals, and would be dafticult to apply to most encrusting species. However, within its limitations it provides a standardlsed framework for morphometric description that may, If applied in future studies, facilitate comparisons of

Table 3 . Diseribution of species among groups predicted by regressien tree analysis (see $\mathrm{Fig} 4$ ) (n $=6$ colonies per species)

\begin{tabular}{|c|c|c|c|c|c|}
\hline & Group 1 & Gtoup 2 & Group 3 & Gresp 4 & Group s \\
\hline Acropora formesá & 0 & 6 & 0 & 0 & 0 \\
\hline Acropora bumills & 0 & 0 & 6 & 0 & 0 \\
\hline Acropora hyacinthus & 0 & 0 & 0 & 3 & 3 \\
\hline Acropora palifera & 6 & 0 & 0 & 0 & 0 \\
\hline Leptovia phrygia & 6 & 0 & 0 & 0 & D \\
\hline Montipora sp. & 0 & 0 & 0 & 1 & 5 \\
\hline Pacillopora damicornis & 0 & 0 & 2 & 9 & 4 \\
\hline Parites anane & 6 & 0 & 0 & 0 & b \\
\hline Pontes cylindrica & 5 & 1 & 0 & 0 & 0 \\
\hline Pantes SpD & 6 & 0 & 0 & 0 & 0 \\
\hline Seriatopora hystrax & 0 & D & 0 & 0 & 6 \\
\hline Stylophorit pistillate & 0 & 6 & 0 & 0 & 0 \\
\hline
\end{tabular}

structural characteristics of corals between different studies and sites.

Commensurate with the range of structural characteristics represented among colonies in this study was large variation in resistance to mechanical force. Colonies of some species, such as Montipora fuberculosa, Serlatopora Aystrix and Pocillopora damicornis, were highly sasceptible to breakage, while others, such as Leptoria phrygia, Porites cylindrica, Porites sp. and Porties annae, were very resistant. The results of the only other published study from the GBR that explicitly tests resistance of whole colonies to mechanical stress (Liddle \& Kay 1987) are consistent with those reponted here. In their study of the effects of trampling on 4 spe. cies of corals. Liddle \& Kay (1987) found that $P$, damicornis was the most susceptible of 4 species exposed to experimental tram. pling, with Acropora palifera relatively resistant to damage and Porites sp. sutfering no structural damage.

The resistance of corals to mechanical damage can be related to quantifiable structural characteristics using non-linear modeling techniques. Four morphometric variables - colony height, branch thickness, branch spacing and colony size-were able to predict the susceptibility of corals 
to breakage with $56 \%$ reliability. Interestingly, other structural characteristics such as skeletal density and branch length, which have been used elsewhere to indicate resistance to breakage in corals, were relatively unimportant in determining resistance in this study. The 4 predictor varinbles can all be easily measured in the field without destructive sampling.

The model resulting from regression tree analysis of these variables is based on colony architecture, yet there was high taxonomic consistency within groups predicted by the model. This sugpests that resistance can be predicted for coral species. at least where there is not large intraspecific variation in structural properties. Where there is large morphological variation among conspecific colonies, it may be mote meaningful to allocate colonies to morphological types (based on preliminary analysisi rather than to taxonomic groups. Although it includes a more numerous and diverse suite of species than has hitherto been attempted in any single study, this model has been developed on a relatively small sub-sample of posnible coral forms. Therefore, despile the relatively strong predictive ability of the model, caution is necessary in attempting to extrapolate to corals with structural mod. els outside the range of those tested here. Further testing of the model on other specles of corals from differ. ent areas would further valudate for invalidatei its general applicability.

The importance of morphological characteristics over skeletal density in corals is particularly interesting. considering the emphasis on density in many studies seeking to explain variation in resistance among corals (e.g. Chamberlain 1978, Schuhmacher 1984, Hughes 1987). This emphasis on sikeletal density is probably due to theoretical predictions and laboratory tests which have shown that porosity has a large effect on the strength of ngid, ceramic-like materials such as coral skeleton (Wainwright et al. 1976, Chamberlain 1976). Maximum skeletal density in corals is constrained by an upper limit of $2940 \mathrm{~kg} \mathrm{~m} \mathrm{~m}^{-3}$, which is the density of solid aragonitic $\mathrm{CaCO}_{3}$ (Graus et al. 1977 ). Pores within the coral skeleton mean that actual densitues (excluding roports based an extremely porous branch tips) commonly range from $<1000 \mathrm{~kg} \mathrm{~m}^{-3}$ to around $2500 \mathrm{~kg} \mathrm{~m}^{-3}$ (Hughes 1987). My measurements of the skeletal density of 12 species of corals encompass a similarly large range, from 1226 to $2201 \mathrm{~kg} \mathrm{~m}$. Yet. 1 tound no correlation between skeletal density and susceptibility of whole colonies to damage from mechanical stress.

The relationship between porosity and strength for ceramic material is described empirically by the function: $\sigma=\sigma_{g} e^{-n V}$, where $\sigma$ is the actual strength of the material, $\sigma_{0}$ is the strength of the same material with no porosity, $V$ is the porosity (the fraction of the total bulk occupied by void), and $n$ is a constant between 4 and 7 (Ryskewitch, in Wainwright et al. 1976). The exponential relationship between strength and porosity means that small changes in porosity cen have a large effect on strength. However the most dense coral skeleton reported to date is $2800 \mathrm{~kg} \mathrm{~m}^{-3}$ (Gladfelter 1982, Hughes 1987) and even this skeleton is 18 to $30 \%$ weaker than solid, void-free aragonite. The skeleton trom the species with highest mean density in this study (Seriatopora hystrix $=2201 \mathrm{~kg} \mathrm{~m}^{-3}$ ) bad a porosity of $25 \%$, which is 63 to $83 \%$ weaker than a solid equivalent. Because the relationship between porosity and strength is exponential. the greatest reduction in strength will occur initially, as pososity increases from zero. At intermediate values of porosity, further increases will have significantly less elfect on strength. For example, doubling porosity from 10 to $20 \%$ causes a much greater reduction in strength than doubling porosity from 40 to $80 \%$. Among the coral species used in this study, the difference in strength between the skeleton of species with the highest (S. hystrix) and lowest mean densities (Porites annae $=1226 \mathrm{~kg} \mathrm{~m}^{-3}$ ) is only 15 to $27 \%$. In most situations, therefore, reductions in strength due to skeletal densities are not likely to be as important as the effects of variation in other structural characteristics. In most instances, greater changes in strength appear to be associated with variations in morphological variables such as colony height and size, branch thickness and branch spacing. This conclusion is supported by a comparison of the relative importance of skeletal density and morphological characteristics for Acropora pafmata and Acropora cervicornis by Schuhmacher 8 Plewka (1981a). They showed that resistance to the mechanical forces of waves is accomplished by adaptations in growth form rather than adaptations in skeletal density, and they concluded that skeletal strength does not appear to be of major adaptive value in the two Acropara species' (Schuhmacher \& Plewka 1981a).

A strong relationship between morphological characteristics and resistance to mechanical damage has also been noted for plants. In particular, the relative sensitivity of perennial plants to trampling appears to be strongly associated with plant morphology (Bates 1935, Kuss 1986, Sun \& Liddle 1993). Morphological features such as leaf size, plant height, internode length and shoot density can all be important in determining resistance to trampling among plants (Sun 8 Liddle 1993. Experimental analyses by Liddie \& Kay (1987) on the effects of trampling on reel-Alat corals found similar patterns: morphological features of colonies (such as branch thickness and branch length) are major determinants of the ability of sessile organisms to resist structural damage. 


\section{Ecological implications of tolerance}

The large variability in tesistance among the species tested here suggests that the adaptive value of breakage will likewise vary considerably between species. Some corals such as Leptoria phrygia, Porites cylindrica and Porites spp. are very unlikely to suffer structural damage, and therefore will rarely produce fragments and need to repair skeletal isjuries. However. fragmentatiot and the need to repair structural damage is likely to be a common occurrence for other spedes such as Montipola sp.. Seriatopora hystrix, Pocillopora damicornls and Acropora hyacinthus. Previous research has shown that the regenerative ability of corals can be ranked according to morphological attributes. Cotals with more solid morphologies (Porites mayen, Pontes lichen and Goniastrea retiformisi are slower to regenerate injury than corals with branching or tabular morphologies (Acropora robusta, P. damicor nis and A. byacinthus) (Hall 1997). Similarly, survival rates of fragments vary among species (Highsmith 1982. Smith \& Hughes 1999), and the ability of a species to establish daughter colonies from broken fragments can be important in determining the net adap. tive value (or cost) to a coral of skeletal damage. However, stochastic events such as disease outbreaks and storm-generated waves exert strong influence on regeneration and fragment survival (Bak \& Criens 1981. Woodlery et al. 1981, Bak et al. 1982l, and the benefits of a strategy which tavours recovery or trag. mentation are likely to be variable and uncertain. Further understanding of the relative benefits of different damage response strategies will require a detailed comparison of the resistance, injury regeneration capacity and fragment survivorship of a range of coral species that span a variety of growth forms.

The biomechanical relationship between colony structure and resistance to damage suggests that the structural characteristics of corals will be important in determining the energy regime which a coral can inhobit. Charies Darwin. in his formative journeys on the 'Beagle'. contrasted the 'great zounded masses' of Porites corals and the 'exceedingly strong honey-combed masses' formed by Millepora colonies which dominated the exposed outer margin of Cocos-Keeling Atoll with the 'generally brittle and thinly branched' species inhabiting the lagoon. By virtue of their structure. 'Porites and Millepora alone seem able to resist the fury of the breakers' (Darwin 1897). Differences among species in their resistance to structural damage have also been suggested as an explanation for differences in community structure between sheltered and exposed reet sltes by recent workers le g. Chamberlain 8 Graus 1975, Graus et al. 1977, Schuhmacher \& Plewka 1981a. Done 1982), and many species show polymorphism in relation to wave exposure ie.g. Geister 1975, Graus et al. 1977, Schuhmacher \& Plewka 1981 a. Veron 1986).

Perhaps the most important role of the structureresistance relationship, however, is in determining bow a coral assemblage responds to physical disturbances, Differential mortality of corals has been reported following many disturbance events which cause mechanical stress, including both natural and anthropogenic disturbances (e.g. Davis 1977, Woodley et al. 1981, Liddle \& Kay 1987, Connell et al, 1997, Rouphael \& Inglis 1998). Many theoretical models which describe mechanisms for maintenance of biological diversity are built on observations that species vary in their tolerance of disturbance events (e.g. Connell 1978). Variability in the tesistance of cosals to structural damage results in patchiness in the effects of a physical disturbance. In some cases disturbances can be critical to prevent a small subset of species trom monopolising resources le.g Connell 1978, Hughes \& Connell 1999). The results of the present study elucidate a mechanism which can explain the differential eftects of physical disturbances. There is a strong relationship between the architectural properties of coral colonies and their resistance to breakage, suggesting that the changes to community composition which result from physical disturbance will depend in part on the morphological characteristics of the coral species which comprise an assemblage.

\section{Resistance and reef management}

The model described in this study has potential application in assessing the risk of damage to different comaunity types from human activities. In many managed reel areas, snch as the Great Barrier Reef Marine Park. the dual goals of preservation and multiple use are approached through the use of zoning plans (Kelleher 1986) In zoning plans which aim to protect reet sites trom physical damage caused by human activities, information about the susceptibility to damage of species comprising the coral assemblage is critical. The strong relationship between colony structure and resistance in corals demonstrated in this study suggests that a framework for predicting the susceptibility to damage of reef sites is practicable. With information on species composition and the structural characteristics of key species, the aggregate of the resistance of the key species can be used to rank reei sites by relative susceptibility to damage. Species can be weighted differently according to their abundance. or by some assessment of ecological or aesthetic value (Done 1995). Finally, information about exposure (i.e. type and frequency of activities; proportion of colonies subjected to mechanical stress) can be combined with 
predictions of susceptibility to estimate the overall risk of damage to the coral assemblage at a particular site. Knowledge of recovery processes, including injury regeneration and fragment survival, would further aid evaluation of the risk of lasting damage to a reef assembloge.

Acknowiedgements. 1 thank $G$. Inglis for many thoughtful discussions and for reviewing this manuscript. I am grateful to A. Baird, N. Marshall, V. Hall, J. OLiver and K. MichalekWagner for comments on this work, to N. Marsball, B. Malina. R. Partridge and J, Kreuger end numerous others for assistence in the tield; to J. E. N. Veron and D. Wachenfeld for providing photoxraphs; and to the staff at One Tree Island Field station for their support. Research was funded by the Cooper. ative Resparch Centre for the Great Barrier Reef World Her. itage Arva.

\section{LTERATURE CTTED}

Allen WH (1992) Increased dangers to Caribbean marine ecosystems. BioScience 42:330-335

Bak RPM, Criens SR (1961) Survival after fragmentation of colonies of Madracis minabilis. Acropora palmate and A. cervicornis [Scleractinit) and the subsequent impact of a coral disease. Proc 4th Int Coral Reet Symp 2:221-227

Bak RPM, Steward-Van Es Y $[1980)$ Regeneration of superficial damage in the scleratinian corals Agaricia agaricites F. purpurea and Parites asteroides. Bull Mar Sci 30. $883-88$ ?

Bak RPM, Brouns J, Heys FML (1977) Regeneration and aspects of spatial competition in the scleractinian corals Agaticia agaricites and Montastrea annularis. Proc 3rd tnt Coral Reet Symp 11143-148

Bak RPM, Termaat RM. Dekker R (1982) Complexity of coral interactions: influence of time, location of interaction and eplfauna. Mar Biol 69:215-222

Bates GH 11935) The vegetation of wayside and hedgerow. $J$ Ecol 23:470-487

Chadwick-Furman NE (1997) Effects of SCUBA diving on coral reet invertebrates in the US Virgin Islands; implications for the management of diving tourism. Proc 6th int Coelenterate Biol Conf $191-100$

Chamberlain JA Jr (1978) Mechanical properties of coral skeleton: compressive strength and its adaptive significance. Paleobiology 4:419-435

Chamberlain JA, Graus RR (1975) Water flow and hydromechanical adaptations of branched reet corals. Bull Mar Sci 25:112-125

Connell J (1978) Diversity in tropical rain forests and coral reefs. Science 199:769-772

Connell JH, Sousa WP [1963) On the evidence needed to judge ecological stability or persistence. Am Nat 121:789-824

Connell JH, Hughes TP, Wallace CC (1997) A 30 year study of coral abundance, recruitment, and disturbance at several scales in space and time. Ecol Monogr 67:461-48B

Craik WR, Kenchington R, Kelleher G (1990) Coral-reef management. In: Dubinsky Z (ed) Ecasystems of the world, coral reefs. Elsevier Science Publishers, New York, p 453-467

Darwin C (1897) The structure and distribution of coral reefs. D Appleton and company, New York

Davies P (1963) Reet growth. In: Barnes D (ed) Perspectives on coral reefs. Brian Clouston Pubtisher, Manuka, p 69-106

Davis GE (1977) Anchar damage to a coral reef on the cosst of
Flarida. Biol Conserv 11:29-34

De'ath G, Fabricius KE (2000) Classification and regression trees a powerful yet simple technique for the analysis of complex ecological data. Ecology (in press)

Dollat S. Tribble G (1993) Recurrent storm disturbance and recovery a long-term study of coral communities in Hawail Coral Reefs 12:223-233

Done TJ (1982) Patterns in the distribution of coral conmunities across the central Great Barrier Reet. Coral Reefs 1 : 95-107

Done TJ (1995) Ecological criteria for evaluating coral reefs and their implications for managers and researchers. Coral Reefs 14:183-192

Endean R (1976) Destruction and recovery of coral reef com. munities. In: Jones OA, Endean R (eds) Biology and geology of coral reefs. Academic Press, New York, p 215-254

Geister $J$ (1975) The influence of wave exposure on the eco. logical zonation of Caribbean coral reefs. Proc Ird Int Coral Reel Symp 1:24-29

Glestetten E (1962) Sketetel develupment in Acropore cervi cornis. III. Patterns of calctum carbonate excretion in the axial corallite. Coral Reefs $1: 45-51$

Grassie JF (1973) Variety in coral reef communities, In: Jones $\mathrm{OA}$, Endean R (eds) Biology and geology of coral reefs. Academic Press, New York, p 247-270

Graus RR, Chamberlain JA Jr, Boker AM (1977) Structural modification in corals in relation to waves and currents, In: Frost S. Weiss MP. Saunders JB (eds) Reefs and related carbonates-ecology and sedimentology. The American Asspciation of Petroleum Cipologists, Tulsa, OK, p 135-153

Hall VR (1997) Interspecific differences in the regeneration of artificial injuries on scleractinian corals. J Exp Mar Biol Ecol 212-9-23

Hall VR, Hughes TP (1996) Reproductive strategies of modular organisms: comparative studies of reef-building corals. Ecology $77 ; 950-963$

Hawkins J, Roberts CM (1992) Effects of recreational SCUBA diving on fore-reef slope communities of coral reefs. Biol Conserv $62: 171=17 \mathrm{~B}$

Hawkins JP, Roberts CM (1993) Effects of recreational SCUBA diving on coral reefs: trampling on ree-flat communities. J Appl Ecol 30:25-30

Highsmith RC (1982) Reproduction by fragmentation in corals. Mar Ecol Pron Ser 7:207-226

Hughes TP (1987) Skeletal density and growth form of corals. Mar Ecol Prog Ser 35:259-266

Hughes TP, Connel JH (1987) Population dynamics based on size or age: a reef-coral analysis. Am Nat 129:818-829

Hughes TP, Connell JH [1999] Multiple stressors on coral reets: a long-term perspective. Limnol Oceanogr 44: $932-940$

Hughes TP, Ayre D, Connell JH (1992) The evolutionary ecology of corals. TREE $7: 292-295$

Jackson JBC $[1979\}$ Morphological strategies of sessile animals. In: Larwood G, Rosen BR (eds) Biology and systematics of colonjel organisms. Acedemic Press, London, p 499-555

Kay AM, Liddle M.J (1989) Impact of buman trampling in dirferent zones of a coral reef flat. Environ Manag 13:509-520

Kelleher G (1986) Managing the Great Barrier Reet. Oceanus $29: 13-19$

Kellomaki S (1973) Talleamisan vaikutus mutik-katypin kuusikon pintakasvillistuuteen. Summary: ground cover response to trampling in a spruce stand of Myrtillus type. Silva Fenn 7:96-113

Kuss FR (1986) A review of major factors influencing plant responses to recreation impacts. Environ Manag 10.637-650

Liddle M, Kay AM (1987) Resistance, survival and recovery 
of trampled corals on the Great Barrier Reef. Biol Conserv 42:1-18

Oliver JK (1984) Intra-colony variation in the growth of Acropora formosa: extension rates and skeletal structures of white (zooxanthellae-free) and brown tipped branches. Coral Reefs 3:139-147

Palaganas VP (1991) Anchor damage on the coral reef of Sombrero Island, Batangas, Philippines. Proc 7th Int Symp Coastal Ocean Manag 1:1-14

Reigl B, Reigl A (1996) Studies on coral community structure and damage as a basis for zoning marine reserves. Biol Conserv 77:269-277

Rinkevich B, Loya Y (1989) Reproduction in regenerating colonies of the coral Stylophora pistillata. In: Spanier E, Steinberger Y, Luris M (eds) Environmental quality and ecosystem stability. ISEEQS Publishers, Jerusalem, p 257-265

Rogers CS (1993) Hurricanes and coral reefs: the intermediate disturbance hypothesis revisited. Coral Reefs 12:127-137

Rouphael AB, Inglis GJ (1998) Impacts of recreational SCUBA diving at sites with different reef topographies. Biol Conserv 82: 329-336

Schuhmacher H (1984) Reef-building properties of Tubastrea micranthus (Scleractinia, Dendrophyllidae), a coral without zooxanthellae. Mar Ecol Prog Ser 20:393-399

Schuhmacher H, Plewka M (1981a) The adaptive significance of mechanical properties versus morphological adjustments in skeletons of Acropora palmata and Acropora cervicornis (Cnidaria, Scleractinia). Proc 4th Int Coral Reef Symp 2:121-128

Editorial responsibility: Rolf Bak (Contributing Editor), Den Burg-Texel, The Netherlands
Schuhmacher H، Plewka M (1981b) Mechanical resistance of reefbuilders through time. Oecologia 49:279-282.

Smith L, Hughes T (1999) An experimental assessment of survival, re-attachment and fecundity of coral fragments. J Exp Mar Biol Ecol 235:147-164

Stoddart D (1963) Effects of Hurricane Hattie on the British Honduras reefs and cays. Atoll Res Bull 95:1-142

Sun D, Liddle MJ (1993) Plant morphological characteristics and resistance to simulated trampling. Environ Manag 17: 511-521

Underwood AJ (1989) The analysis of stress in natural populations. Biol J Linn Soc 37:51-78

UTHSCSA (1998) ImageTool.1.28. University of Texas Health Science Centre at San Antonio (accessed: 5/3/1999); available at http://ddsdx. uthscsa.edu/dig/itdesc.html

Veron J (1986) Corals of Australia and the Indo-Pacific. Angus and Robertson, North Ryde

Wagar JA (1967) Simulated trampling as a technique in recreation research. XIV IUFRO Congress Munchen Section 26:239-245

Wainwright SA, Biggs WD, Currey JD, Gosiine JM (1976) Mechanical design in organisms. Edward Arnold (Publishers) Limited, London

Woodley JD, Chornesky EA, Clifford PA, Jackson JBC, Kaufman LS, Knowlton NC, Lang JC, Pearson MP, Porter JW Rooney MC, Rylaarsdam KW, Tunnicliffe WJ, Wahle CM, Wulff JL, Curtis SG, Dallmeyer MD, Jupp BP, Koehl MAR, Neigel J, Sides EM (1981) Hurricane Allen's impact on Jamaican coral reefs. Science 214:749-755

Submitted: May 4, 1999; Accepted: October 12, 1999

Proofs received from author(s): June 26, 2000 